\title{
Enhancement of Heat Transfer Using $\mathrm{Fe}_{3} \mathrm{O}_{4}$ / Water Nanofluid with Varying Cut-Radius Twisted Tape Inserts
}

\author{
K.P.V. Krishna Varma ${ }^{1 *}$, P.S. Kishore ${ }^{2}$ and P.V. Durga Prasad ${ }^{3}$ \\ ${ }^{1}$ Associate Professor, Department of Mechanical Engineering, CMR College of Engineering \&amp; \\ Technology, Kandlakoya, Medchal Road, Hyderabad-501401,Telangana, India. \\ ${ }^{1}$ Orcid id:0000-0002-2518-813X \\ 2 Professor, Department of Mechanical Engineering,Andhra University, Waltair Junction \\ Visakhapatnam-530003, Andhra Pradesh, India. \\ ${ }^{3}$ Associate Professor, Department of Mechanical Engineering, MVSR Engineering College, Saroor Nagar \\ Mandal, Ranga Reddy District, Nadergul, Hyderabad-501510,Telangana, India.
}

\begin{abstract}
An attempt is made to enhance the rate of heat transfer in heat exchangers using $\mathrm{Fe}_{3} \mathrm{O}_{4}$ nanofluid. In this work an experimental analysis on twisted tape inserts with varying cutradius in Hair pin heat exchanger using $\mathrm{Fe}_{3} \mathrm{O}_{4}$ water based nanofluid is presented. Experimental data is generated at the mass flow rates of ranging from $0.05 \mathrm{Kg} / \mathrm{s}$ to $0.25 \mathrm{Kg} / \mathrm{s}$ and the Reynolds number ranging between 3000 to 25000.where as the flow rate of the hot fluid in the annulus is maintained constant $(0.1 \mathrm{Kg} / \mathrm{s})$. The Heat transfer coefficient and corresponding friction factors required for performance analysis are determined for various particle volume concentrations of $0.01 \%$ and $0.03 \%$. The Nusselt number of entire pipe for $0.03 \%$ concentrations of nanofluid with radius of cut, $r=6$ insert of $\mathrm{H} / \mathrm{D}=3$ is enhanced by $32.01 \%$ as compared water. The friction factor of entire pipe for $0.03 \%$ concentration of nanofluid with radius of cut, $r=6$ twisted tape insert of $\mathrm{H} / \mathrm{D}=3$ is enhanced by 1.21 times as compared to water. The results of the investigation shows an enhancement in the performance parameter of the heat exchanger namely heat transfer coefficient friction factor with an increase in volume concentration of the nanofluid.
\end{abstract}

Keywords: Ferric oxide nanofluid, particle volume concentration, heat transfer coefficient, varying cut radius twisted tape insert.

\section{INTRODUCTION}

Intensification in heat transfer in an industrial process may lead to saving in energy, reduce process time and lengthen the working life of the equipment. Enhancement in heat transfer can be achieved by either passive methods which does not require external power or active methods, which require external power. Bergles [1] Twisted tape techniques have been used to augment heat transfer in double pipe heat exchanger. P.K. Sharma et.al. [2] Presented a new approach to predict the convective heat transfer coefficient in a tube with twisted tape inserts of different types of pitch to diameter ratios. Modification is proposed to Van Driest eddy diffusivity expression to the case of swirl flow generated by twisted tape inserts. Heat transfer efficiency can be increased by increasing the thermal conductivity of the working fluid. Water, ethylene glycol and engine oil which are commonly used as heat transfer fluids have relatively low thermal conductivities when compared to that of the solids. High thermal conductivity of solids can be used to increase the thermal conductivity of a fluid by adding small solid particles to that fluid. K.V.Reddy et.al. [3] Double pipe heat exchangers are simple in construction and efficient in operation. Enhancement in heat transfer in heat exchangers can be achieved by using different techniques. Et.al $[4,5,6,7]$ Passive technique is one of the best methods in this insertion of twisted tape inserts increase the heat transfer coefficient, increase turbulence and thus increase the rate of heat transfer insides the tubes of the heat exchanger. Cut twisted taped further increase the turbulence which enhances the turbulent heat transfer. Pak and Cho [8] performed experiments on convective heat transfer of nanofluids under turbulent flow conditions using $\mathrm{Al}_{2} \mathrm{O}_{3}$ and $\mathrm{TiO}_{2}$ dispersed in water. P.V.Durga Prasad et.al. [9] carried out experimental investigation to enhance the heat transfer by using Aluminum oxide nanofluids at low volume concentrations and trapezoidal cut twisted tapes .

The results showed that there is a significant enhancement in heat transfer with nano fluids when compared with that of the base fluid and the trapezoidal cut twisted tapes enhanced the turbulence which in turn increased the rate of heat transfer. B. Raei et.al.[10] Measured overall heat transfer coefficient and friction factors of water based $\gamma-\mathrm{Al}_{2} \mathrm{O}_{3}$ nanofluid in a double pipe heat exchanger and results are demonstrated that increasing the concentration of nanofluid, flow rate and inlet temperatures increase the overall heat transfer coefficient and 
heat transfer rate. V. Murali Krishna et.al. [11] Conducted experiments to study the heat transfer rates of $\mathrm{Al}_{2} \mathrm{O}_{3}$-water nanofluids for different flow rates and volume concentrations in a concentric tube heat exchanger. Comparative analysis has been carried between nanofluid and base fluids. Heat transfer coefficients are determined using correlations available in the literature. Hiregoudar Y et.al. [12] Carried out CFD analysis considering four different nanofluids (Magnesium oxidewater, copper oxide-water, Titanium oxide-water, and Iron oxide-water). From the obtained results it is found that Magnesium oxide - water based nanofluids shows higher heat transfer rates when compared to other nanofluids. Ebenezer Paul et.al. [13] Investigated numerically heat transfer, friction and thermal performance characteristics of $\mathrm{CuO}$-water nanofluid, twisted tape with alternate axis with nanofluid particle volume concentrations are varied but the twist ratio remained constant. The results showed that with the increase in particle volume concentration, heat transfer coefficient increases. Thus there is an increase in rate of heat transfer. R. Dharmalingam et.al.[14] carried out experimental study on heat transfer characteristics of water based Aluminum oxide nanofluid in a counter, parallel flow direction in a shell and tube heat exchanger in this the overall heat transfer coefficient increases with increase in mass flow rate of the nanofluid. The Nusselt number increased with mass flow rate irrespective of the flow direction and also the flow direction, LMTD decreased with increase in mass flow rate. Gamit Sandip D et.al. [15] Performed simulation and experimental investigation in a double pipe concentric tube heat exchanger with inner and annular twisted tape inserts. It is found that the double pipe with annular twisted tape enhance heat transfer than the other twisted tape in the tube.

\section{EXPERIMENTAL SETUP AND PROCEDURE}

\section{Preparation of Nanofluid}

Ferric Oxide Nanopowder is procured from Sigma-Aldrich Chemicals, USA [20] and two step methods is used to prepare Ferric Oxide nanofluids required for the present work. The thermo- physical properties of $\mathrm{Fe}_{3} \mathrm{O}_{4}$ nanoparticles are reported in Table $\mathbf{1 .}$

Table 1: Thermo physical properties of $\mathrm{Fe}_{3} \mathrm{O}_{4}$ nanoparticles and base fluid.

\begin{tabular}{|c|c|}
\hline Nanofluid & Ferric Oxide $\left(\mathrm{Fe}_{3} \mathrm{O}_{4}\right)$ \\
\hline Diameter & $<50 \mathrm{~nm}$ \\
\hline Purity & $99 \%$ \\
\hline Density & $5180 \mathrm{Kg} / \mathrm{m}^{3}$ \\
\hline Specific Heat & $104 \mathrm{~J} / \mathrm{KgK}$ \\
\hline Thermal Conductivity & $17.65 \mathrm{~W} / \mathrm{m}-\mathrm{K}$ \\
\hline
\end{tabular}

Two concentrations of Ferric Oxide Nanofluids with $0.01 \%$ and $0.03 \%$ are prepared by mixing the Ferric Oxide nanoparticles in distilled water. For $0.01 \%$ concentration: 1 gram of Sodium Laurel Sulphate (surfactant) is first mixed in 20 liters of water and stirred thoroughly. Then 10.1 grams of Ferric Oxide Nanopowder is added to the water and this mixture is stirred by using a high speed stirrer for about 45 minutes to obtain a nanofluid mixture. For $0.03 \%$ concentration: 3 grams of Sodium Laurel Sulphate (surfactant) is first mixed in 20 liters of distilled water and stirred thoroughly and 31 grams of Ferric Oxide Nanopowder is added to the water and this mixture is stirred using a mechanical stirrer for about 45 minutes to obtain a stable nanofluid. The Ferric oxide nanopowder is shown in Fig. 1a and is used to prepare nanofluids of $0.01 \%$ concentration and $0.03 \%$ concentration is as shown in Fig. $1 \mathrm{~b}$ and Fig. $1 \mathrm{c}$.

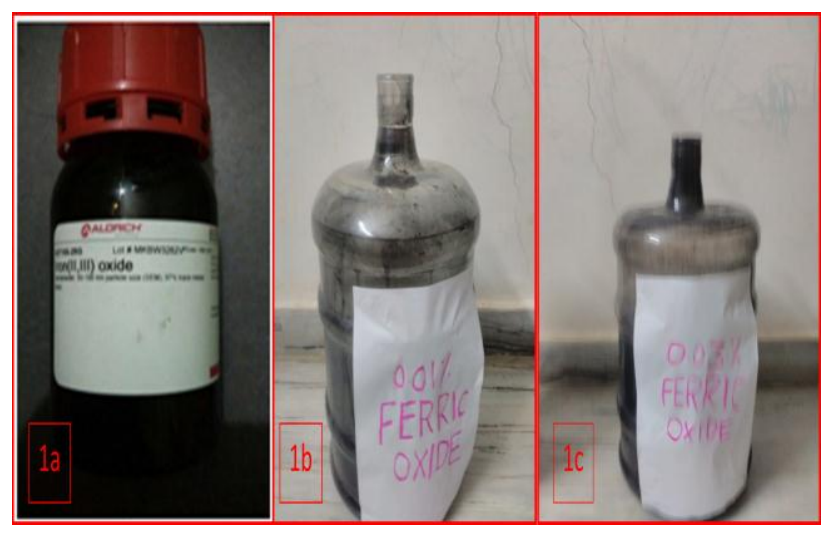

Figure 1a: Ferric Oxide Nano Powder, Fig.1b Nano fluids $0.01 \%$ concentration, Fig.1c.Nano fluid $0.03 \%$ concentration

\section{Experimental setup and working procedure}

The representation of the experimental setup photograph is shown in Fig. 2. The experimental setup test section consists of a shell with two tubes, two U-bends, flow meters, chiller, hot fluid tank, cold fluid tank, pumps, bypass valve arrangement and a U-tube manometer. The test section consists of a U-bend double pipe heat exchanger; the inner tube is made of copper and its diameter (ID) is $0.017 \mathrm{~m}$, and the annulus tube is made of mild steel and its diameter is 0.06 $\mathrm{m}$. The length of the inner tube is $5.6 \mathrm{~m}$ and the bend is equidistant from both ends at a distance of $120 \mathrm{~mm}$; with a radius of $60 \mathrm{~mm}$. The inner tube is concentric to the annulus tube and is enclosed by it. The system consists of two circuits. One is hot water circuit and another one is working fluid circuit. The hot water with steady temperature of $70^{\circ} \mathrm{C}$ is pumped through the annular region and in the working fluid/nanofluid flows through the inner tube by using a pump. The mass flow rates for both hot and cold fluids are controlled with by-pass valve arrangement. Two flow meters are used to measure the mass flow rates of water based nanofluid and hot fluid. Throughout the experiments, the mass flow rate of hot fluid through the annulus is kept constant $(0.1 \mathrm{~kg} / \mathrm{s})$ and mass 
flow rate of nanofluid is varied from $0.05 \%$ to $0.25 \mathrm{~kg} / \mathrm{s}$. The heat transfer coefficients for the inner and outer pipes are calculated, the surface area related to the bend region is relatively small compared to the surface areas of the inner and outer pipes. Therefore, the heat transfer in the bend region can be neglected with no significant loss of accuracy. The outside of the annulus tube is wounded with $20 \mathrm{~mm}$ diameter asbestos rope insulation to minimize the heat loss from the test section to the surroundings. Nanofluid is pumped to inner pipes in counter flow direction through flow meter. The nanofluid runs in closed loop. The Nanofluid coming out from the tubes is passed through a chiller to cool it and send it back into the tubes at a constant inlet temperature of $28^{\circ} \mathrm{C}$. In order to measure the temperature of both fluids at the inlet and the outlet is measured with the help of eight $\mathrm{K}$ - type thermocouples. Thermocouple needles are connected to the data acquisition system and the thermocouple readings are recorded in the computer for further processing. The thermocouples are calibrated $\left( \pm 0.1 \%{ }^{0} \mathrm{C}\right)$ before placing in the test section. Differential pressure of fluid in inner pipes at inlet and outlet can be measured with the help of a U-tube manometer. The tube is cleaned with pure water in between the experiments conducted with the nanofluid.

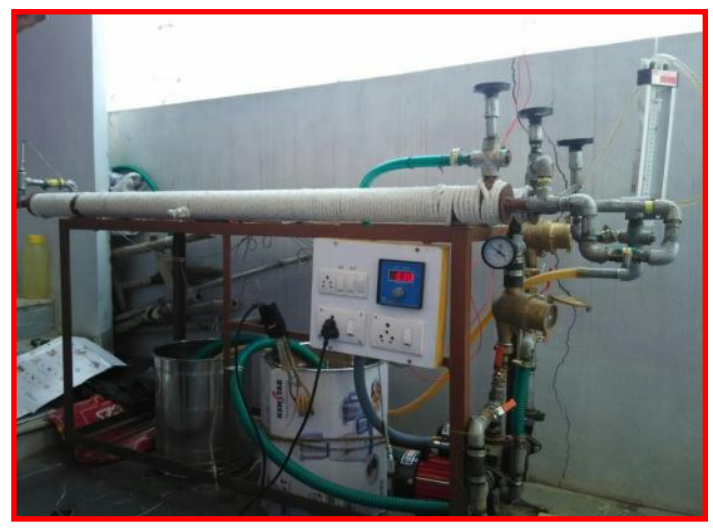

Figure 2: Photograph of experimental setup

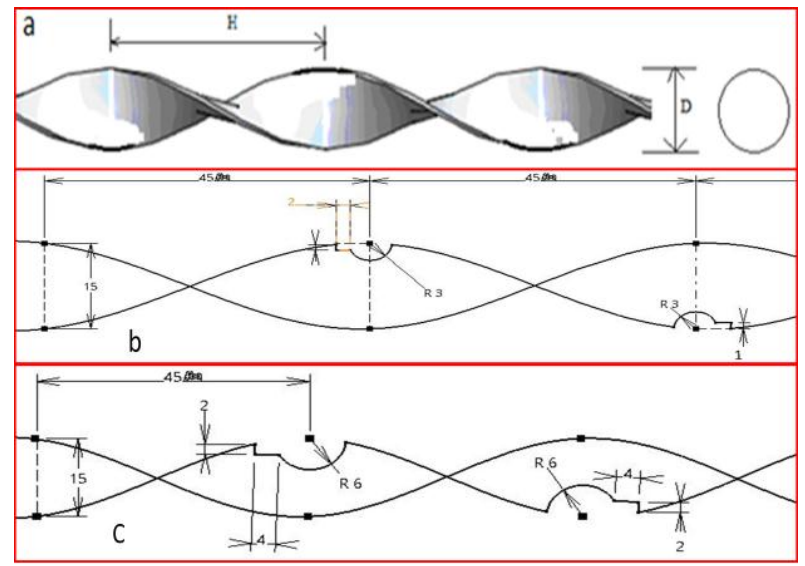

Figure 3: The geometric shapes of the variable cut twisted tapes in $\mathrm{mm}$ (a) twisted tape (b) cut radius with $\mathrm{r}=3$, (c) cut radius with $r=6$

\section{Uncertainty Analysis}

Due to the errors in the measurement, the values of Nusselt number and friction factor vary from the estimated values. Hence, uncertainty analysis is carried out using Beckwith et al. [16] considering the measurement errors whereas the possible errors in the fluid properties are not included. The calculations indicated that the uncertainties involved for present study, the estimation are $\pm 1.5 \%$ and $\pm 1.3 \%$, respectively.

\section{Data Analysis}

\section{Thermo physical properties of nanofluids}

The thermo physical properties (density, specific heat, viscosity and thermal conductivity) of the nanofluid are calculated as a function of nanoparticle volume concentration together with properties of base fluid and nanoparticles. The density and specific heat of nanofluid is evaluated using the general formula for the mixture:

$$
\begin{gathered}
\rho_{n f}=\phi \rho_{p}+(1-\phi) \rho_{b f} \\
C_{p_{n f}}=\phi C_{p_{p}}+(1-\phi) C_{p_{b f}}
\end{gathered}
$$

These equations have been found appropriate for nanofluids through experimental validation by Pak and Cho [8]. The thermal conductivity are calculated from Maxwell model [21] as shown in Eq. (3) which is recommended for homogeneous and low volume concentration liquid-solid suspensions with randomly dispersed, uniformly sized and non interacting spherical particles.

$$
k_{n f}=k_{b f}\left[\frac{k_{p}+2 k_{b f}+2 \phi\left(k_{p}-k_{b f}\right)}{k_{p}+2 k_{b f}-\phi\left(k_{p}-k_{b f}\right)}\right]
$$

Viscosity of nanofluids is calculated with the general Einstein's formula [22].

$$
\mu_{n f}=\mu_{b f}(1+2.5 \phi)
$$

Where $(\mu)$ is the viscosity and the subscripts $(p)_{s}(b f)$ and $(n f)$ refer to particle, base fluid and nanofluid, respectively.

\section{Varying Cut- Radius Twisted Tapes}

Twisted tapes of $3 \mathrm{~mm}$ thick, $1 \mathrm{~m}$ length and with $\mathrm{H} / \mathrm{D}$ ratio of 3 is used for the experimental analysis and varying cut is provided on the periphery of the surface on alternative sides of the tape. The dimensions of the cut-radius of being $3 \mathrm{~mm}$ and $6 \mathrm{~mm}$, length of cut being $2 \mathrm{~mm}, 4 \mathrm{~mm}$, width $1 \mathrm{~mm}$, $2 \mathrm{~mm}$. The varying cut-radius twisted tape geometry is as shown in the Fig.3. Two varying cut-radius twisted tape 
inserts are placed at the upstream of the hair pin heat exchanger to carry out the analysis. This is because as the working fluid enters the upstream of the heat exchanger, the velocity will be more. When the twisted tapes are provided at the upstream, the velocity of the working fluid increases and the retention time increases.

\section{Heat transfer and friction factor}

The data reduction of the measured results is summarized in the following procedures. The mean Nusselt number and friction factor are based on the inside diameter of the plain tube. Heat transfer to the cold fluid in the tube, $Q_{c}$ in the test tube can be determined using

$$
\mathrm{Qc}=\mathrm{m}_{\mathrm{c}} \mathrm{C}_{\mathrm{pc}}\left(\mathrm{T}_{\mathrm{co}}-\mathrm{T}_{\mathrm{ci}}\right)
$$

Where, $\mathbf{m}_{\mathbf{c}}$ is the mass flow rate of cold water, $\mathbf{C}_{\mathbf{p c}}$ is the specific heat of cold water, $\mathrm{T}_{\mathrm{ci}}$ and $\mathrm{T}_{\mathrm{co}}$ are the cold water inlet and outlet temperatures respectively.

The heat transfer rate from the hot water in the annulus side, $\mathrm{Q}_{\mathrm{h}}$ can be written as

$$
\mathrm{Q}_{\mathrm{h}}=\mathrm{m}_{\mathrm{h}} \mathrm{C}_{\mathrm{ph}}\left(\mathrm{T}_{\mathrm{hi}}-\mathrm{T}_{\mathrm{ho}}\right)
$$

Here, $Q_{h}$ is the mass flow rate of hot water, $C_{p h}$ is the specific heat of water, $\mathrm{T}_{\mathrm{hi}}$ and $\mathrm{T}_{\text {ho }}$ are the hot water inlet and outlet temperatures respectively.

The average heat transfer rate $\mathrm{Q}_{\text {ave }}$ used in the calculation is estimated from the hot water and cold water sides as follows:

$$
\mathrm{Q}_{\mathrm{ave}}=\left(\mathrm{Q}_{\mathrm{c}}+\mathrm{Q}_{\mathrm{h}}\right) / 2
$$

For fluid flows in a concentric tube heat exchanger, an overall heat transfer coefficient $(U)$ is calculated from:

$$
\hat{Q}_{\text {avg }}=U A_{i}(\Delta T)_{\text {LNTD }}
$$

Where $A_{i}=\pi d_{i} L$

$$
\text { Inner region } \Rightarrow(\Delta T)_{\text {LWTD }}=\frac{\left(T_{g}-T_{1}\right)-\left(T_{7}-T_{2}\right)}{\ln \left(\frac{T_{g}-T_{1}}{T_{y}-T_{2}}\right)}
$$

The tube-inside heat transfer coefficient $h_{i}$ is determined by using

$$
\frac{1}{U_{i}}=\frac{1}{h_{i}}+\frac{r_{i}}{k} \ln \frac{r_{0}}{r_{i}}+\frac{r_{1}}{r_{0}} \times \frac{1}{h_{0}}
$$

The average Nusselt number based on the inner diameter of the tube, was then evaluated by

$$
N u=\frac{h_{\mathrm{i}} \mathrm{x} d \mathrm{~h}_{\mathrm{f}}}{k}
$$

The Reynolds number is based on the flow rate at the inlet of the tube.

$$
R e=\frac{\rho v d_{h}}{\mu}
$$

Where $\mu$ is the dynamic viscosity of the working fluid.

Friction factor, $\mathrm{f}$ can be calculated from

$$
f=\frac{\Delta P}{(L D)\left(\rho v^{2} / 2\right)}
$$

Where $\Delta p$ is the pressure drop across the test section, $\rho$ is the density of working fluid, $d_{i}$ is the inner diameter of tube, $u$ is the velocity of working fluid, and $\mathrm{L}$ is the length of tube.

\section{RESULTS AND DISCUSSION}

\section{Validation of the experimental data for the plain tube}

With the help of data obtained from the experiments and with the Nusselt number and friction factor, the experimental setup is validated by using water as working fluid and the average Nusselt number (average between inner and outer pipe) for water is shown in Fig. 4 along with the data, Eq. (13) of Notter-Rouse [17] and Eq. (14) of Gnielinski [16]. The difference between experimental and theoretical Nusselt number for water was obtained a maximum of $\pm 3 \%$.

The available Nusselt number correlations for single phase fluid are given below:

(i) Notter-Rouse [17] equation

$$
\text { Nu } u=5+0.015 R^{0.856} P_{r}^{0.347}
$$

$$
2300<\text { Re }<10^{6}, 0.5<\text { Pr }<2000
$$

(ii) Gnielinski [16] equation

$$
\begin{gathered}
\text { Nu }=\frac{\left(\frac{I}{n}\right)(R e-1000) p_{r}}{1.07+127\left(\frac{f}{n}\right)^{0.5}\left(p_{r}^{n / n-1)}\right.} \\
f=(1.58 \ln (R e)-3.82)^{-2}, 2300<R e<10^{6}, \\
0.5<P_{r}<2000
\end{gathered}
$$

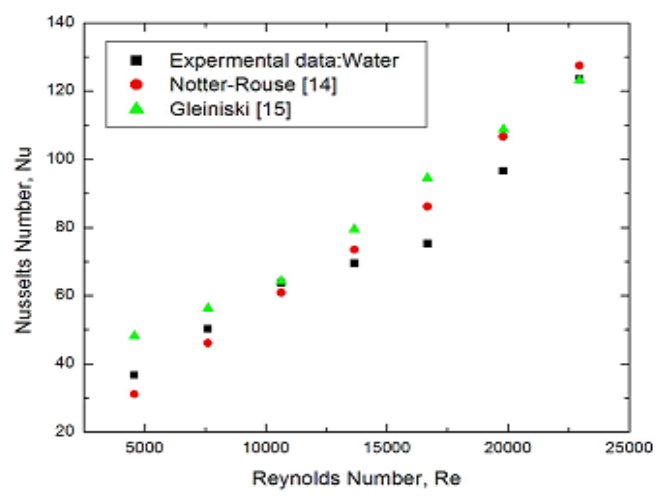

Figure 4: Validation of experimental Nusselt number of base fluid with the data of and Notter-Rouse [17] and Gnielinski [16] 
Since the fluid flow is fully developed turbulent flow, the friction factor of inlet and outlet pipe is neglected. The friction factor of entire pipes is considered for analysis. Friction factor experiments for water are conducted initially and the values are estimated from Eq. (12). Fig. 5 represents the experimental friction factor of water is in comparison with the data obtained from Eq. (15) of Blasius [18] and Eq. (16) of Petukov [19] and found to be a maximum of $\pm 2.2 \%$ deviation. The available friction factor correlations for single phase fluid are given below:

(i) Blasius [18] equation

$$
\mathrm{f}=0.3164 \operatorname{Re}^{-0.25}, 3000<\operatorname{Re}<10^{5}
$$

(ii) Petukov [19] equation

$$
\mathrm{f}=(0.790 \ln \mathrm{Re}-1.64)^{-2}, 2300<\operatorname{Re}<5 \times 10^{6}
$$

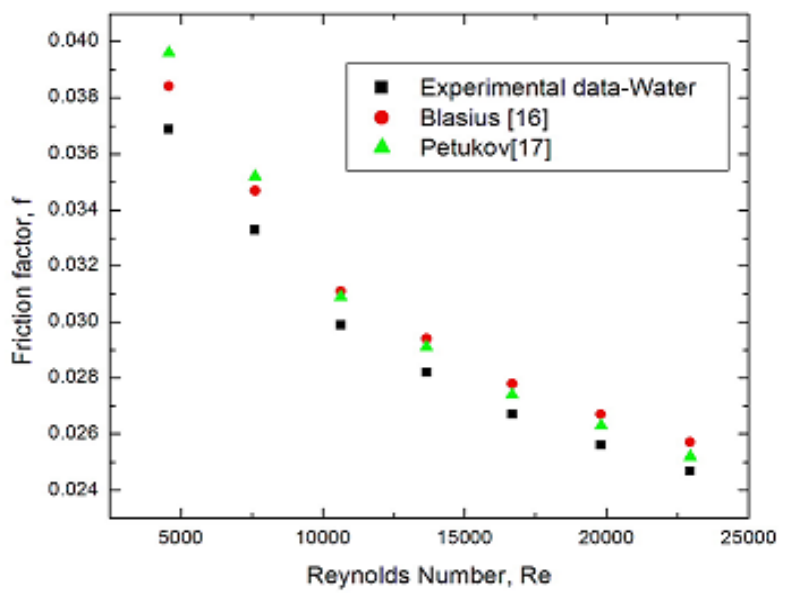

Figure 5: Friction factor of water compared with Blasius [18] and Petukov [19].

\section{Effect of variable cut-twisted tape on heat transfer augmentation}

The experimental investigations on heat transfer for the plain tube and variable cut-twisted tapes with radius $(r=0, r=3, r=6)$ for the flow of water and water with nanofluid mixture with low volume concentration of $0.01 \%$ and $0.03 \% \quad \mathrm{Fe}_{3} \mathrm{O}_{4}$ nanofluid are calculated and presented in Fig.6. Compared water data with $0.03 \%$ volume concentration of nanofluid in a tube with $H / D=3, r=6$, the Nusselt number enhancement is $19.50 \%$ and $32.01 \%$ within the Reynolds number range of 4586 and 22932, respectively. Compared to the plain tube, the tubes with variable cut-radius twisted tapes with radius, $r=6$ exhibit higher Nusselt number, because the tape inserts create swirl flow offering a longer flowing path of fluid flow through the tube and also better fluid mixing, resulting in a thinner thermal boundary layer along the tube wall and thus better convective heat transfer.

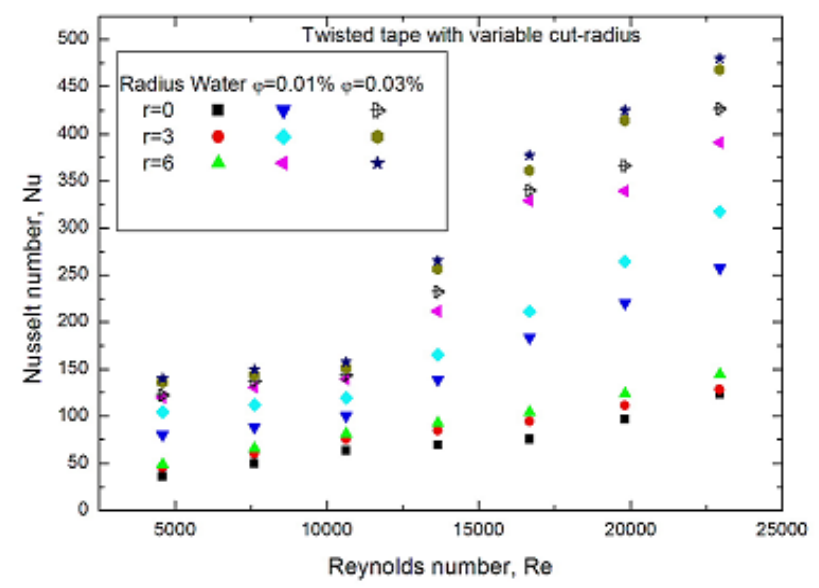

Figure 6: Comparison of experimental data of water, $\mathrm{Fe}_{3} \mathrm{O}_{4}$ nanofluid in a tube with variable cut- twisted tape inserts

\section{Effect of variable cut-twisted tape on friction factor}

The use of nanoparticles in the base fluid, the friction factor is slightly increased. But this is irrelevant penalty in heat transfer enhancement, though the friction factor of nanofluid increases with increase of Reynolds number and particle concentrations is shown in Fig.7. This can be caused by the increase of shear force on tube barrier acted by the larger numbers of nanoparticles. It seems that, the nanofluids with concentrations of $0.03 \%$ by volume provide average friction factors higher than the base fluid by around $5.8 \%$ and $7.6 \%$ in the Reynolds number of 4586 and 22932, respectively. It is clear that the use of variable cut-radius twisted tape results in a very high friction factor than that of plain tube. The friction factor of $0.03 \%$ nanofluid flowing in a tube with $\mathrm{H} / \mathrm{D}=3, \mathrm{r}=6$ enhances 1.14 times at a Reynolds number of 4586 and 1.21 times at a Reynolds number of 22932 compared with water.

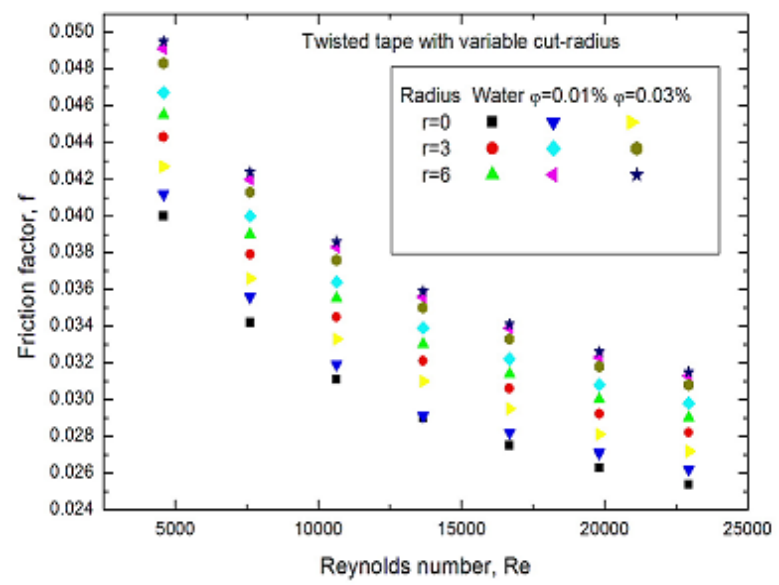

Figure 7: Comparison of experimental friction factor of $\mathrm{Fe}_{3} \mathrm{O}_{4}$ nanofluid in a tube with variable cut- twisted tape insert 


\section{Thermal performance factor}

The thermal performance factor $(\eta)$ can be defined as the ratio of the heat transfer coefficient (or Nusselt number) ratio to the friction factor (or pressure drop) ratio at the same pumping power:

$$
\eta=\frac{\left(\frac{\square \text { nf,insert }}{\square \text { straig } \square t}\right)}{\left(\frac{f_{n f, \text { insert }}}{f_{\text {straig } \square t}}\right)^{n}}
$$

where $n$ is the value index. The larger the values of the thermal performance factor, the more suitable the enhancement heat transfer technique. The value index $(n)$ is experienced different values in previous literatures. In the laminar flow condition, Usui et al. [23] and Suresh et al. [24] have considered $n=0.1666$ and Hashemi and AkhavanBehabadi [25] have taken $n=1.0$. In the turbulent flow condition, Wongcharee et al. [26] and Abbasian Arani and Amani [27] have considered, $n=1 / 3$.

The results of thermal performance factor based on the same mass flow rate criteria are shown in Fig. 8. Evidently, nanofluids with higher concentration of $\mathrm{Fe}_{3} \mathrm{O}_{4}$ nanoparticles yield higher thermal performance factors. The effect of the presence of variable cut-radius twisted tape inserts on thermal performance factor is also principally governed by the influence of heat transfer improvement. For the range considered, the maximum thermal performance factor of 1.17 is observed by using nanofluid of $0.03 \%$ volume concentration in the entire pipes using variable cut-radius twisted tape inserts of $\mathrm{H} / \mathrm{D}=3, \mathrm{r}=3$ at a Reynolds number of 22592.

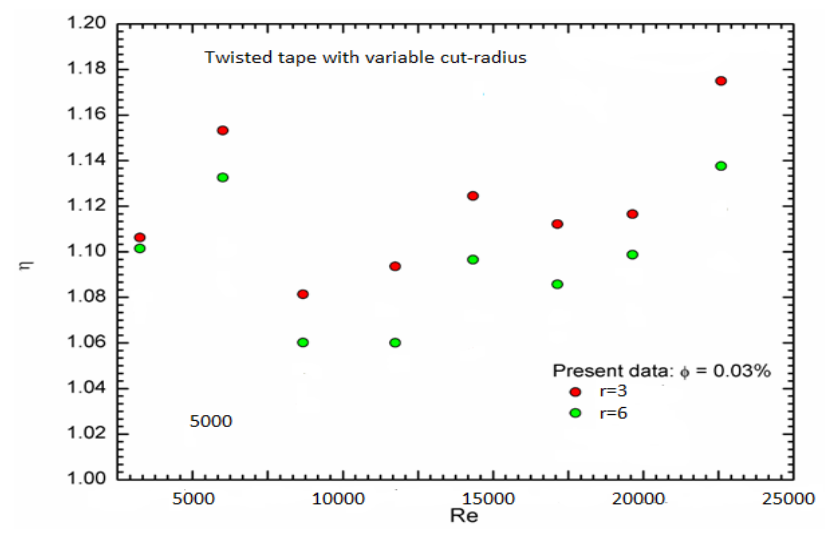

Figure 8: Comparison of thermal performance factor for $0.03 \% \mathrm{Fe}_{3} \mathrm{O}_{4}$ nanofluid in a tube with Variable cutradius twisted tape insert

\section{CONCLUSIONS}

The heat transfer and friction factor analysis have been experimentally performed on the water based $\mathrm{Fe}_{3} \mathrm{O}_{4}$ nanofluid in the pipes with return bend and variable cut-radius twisted tape inserts. The results show that the average Nusselt numbers increase with an increase of Reynolds number and the nanoparticle volume concentration. However, the concentration increment of the nanofluid is accompanied by the high pressure drop in the pipe. Under the same Reynolds number, the average Nusselt number of entire pipe for $0.03 \%$ concentrations of $\mathrm{Fe}_{3} \mathrm{O}_{4}$ nanofluid with variable cut-radius twisted tape inserts of $\mathrm{H} / \mathrm{D}=3, \mathrm{r}=6$ is enhanced by $32.01 \%$ as compared to water. The friction factor of entire pipes for $0.03 \%$ concentration of nanofluid with variable cut-radius twisted tape inserts of $\mathrm{H} / \mathrm{D}=3, \mathrm{r}=6$ is enhanced by 1.21 times as compared to water. Convective heat transfer, friction factor as well as thermal performance factor associated with the simultaneous application of nanofluid and variable cut-radius inserts are higher than those associated with the individual techniques.

\section{NOMENCLATURE}

$\mathrm{d}_{\mathrm{i}}=$ Inside diameter of the tube, $\mathrm{m}$

$\mathrm{d}_{\mathrm{o}}=$ Outside diameter of the tube, $\mathrm{m}$

$\mathrm{L}=$ Length of the tube, $\mathrm{m}$

$\mathrm{T}_{\mathrm{ci}}=$ Inlet temperature of the cold fluid, ${ }^{0} \mathrm{C}$

$\mathrm{T}_{\text {co }}=$ Outlet temperature of the cold fluid, ${ }^{0} \mathrm{C}$

$\mathrm{T}_{\mathrm{hi}}=$ Inlet temperature of the hot fluid, ${ }^{0} \mathrm{C}$

$\mathrm{T}_{\text {ho }}=$ Outlet temperature of the hot fluid, ${ }^{0} \mathrm{C}$

$\mathrm{h}_{\mathrm{i}}=$ Inner heat transfer coefficient, $\mathrm{w} / \mathrm{m}^{2} \mathrm{~K}$

$\mathrm{h}_{\mathrm{o}}=$ Outer heat transfer coefficient, $\mathrm{w} / \mathrm{m}^{2} \mathrm{~K}$

$\mathrm{K}=$ Thermal conductivity, $\mathrm{W} / \mathrm{mK}$

$\mathrm{Nu}=$ Nusselt Number

Re $=$ Reynolds Number

$\mathrm{r}=$ radius

\section{Greek Symbols}

$p$ Pressure drop

$\Delta T$ Logarithmic mean temperature difference $\varphi$ Volume concentration of nanoparticles, \% $\mu$ Dynamic viscosity, $\mathrm{kg} / \mathrm{m}^{2} \mathrm{sec}$

$P$ Density, $\mathrm{kg} / \mathrm{m}^{3}$

$\alpha$ Thermal diffusivity, $\mathrm{m}^{2} / \mathrm{s}$

\section{Subscripts}

$c$ Cold fluid

Exp Experimental

$h$ Hot fluid

$i$ Inlet

$o$ Outlet 


\section{REFERENCES}

[1] A.E.Bergles, 1995,Techniques to enhance Heat transfer, HandBook of Heat Transfer, Mc Graw Hill, Chapter 11 .

[2] P.K.Sarma , T. Subramanyam , P.S. Kishorea, V. Dharma Rao, Sadik Kakac ,2002, A new method to predict convective heat transfer in a tube with twisted tape inserts for turbulent flow, Journal of Thermal Sciences, pp 955-960.

[3] K.Vijaya Kumar Reddy , Naga Sarada Somanchi, Rangisetty Sri Rama Devi, Ravi Gugulothu and B. Sudheer Prem Kumar ,2015, Heat Transfer Enhancement in a Double pipe Heat Exchanger Using Nano Fluids, Proceedings of the 17th ISME Conference ISME17 October 3-4, 2015, IIT Delhi, New Delhi,PP:1-7

[4] Indrakant Singh, D.R.Nilesh Diwakar , 2013, Heat transfer enhancement using different geometry of twist tape turbulators: a review, International Journal of Applied Research in Mechanical Engineering (IJARME) ISSN: 2231 -5950, Vol-3, Iss-2,

[5] S.Tabatabaeikia, H.A.Mohammed, N.Nik-Ghazali, and B.Shahizare, 2014, Heat Transfer Enhancement by Using Different Types of Inserts, Advances in Mechanical Engineering, Article ID 250354, pp:1-13.

[6] Mukesh P Mangtani and K M Watt, April 2015, Effect of Twisted-tape inserts on heat transfer in a tube-a review, , ISSN 2278 - 0149 ,Vol. 4, No. 2.

[7] A Dewan, P Mahanta, K Sumithra Raju and P Suresh Kumar,Review of passive heat transfer augmentation techniques, Proc. Instn Mech. Engrs Vol. 218 Part A: J. Power and Energy.

[8] Pak, B.C., Cho Y.I. 1998, Hydrodynamic and heat transfer study of dispersed fluids with submicron metallic oxide particles, Experimental Heat Transfer 11, pp 151-170.

[9] P.V. Durga Prasad, A.V.S.S.K.S. Gupta and K. Deepak, 2014, Investigation of Trapezoidal-Cut Twisted Tape Insert in a Double Pipe U-Tube Heat Exchanger using $\mathrm{Al}_{2} \mathrm{O}_{3}$ /Water based Nanofluid, 2nd International Conference on Nanomaterials and Technologies (CNT 2014), Procedia Materials Science10( 2015 ) 50-63,Pp: 50-63

[10] B. Raei1, F. Shahraki1, M. Jamialahmadi, S.M. Peyghambarzadeh, 2017, Experimental investigation on the heat transfer performance and pressure drop characteristics of $\gamma-\mathrm{Al}_{2} \mathrm{O}_{3}$ /water nanofluid in a double tube counter flow heat exchanger, Trans. Phenom. Nano Micro Scales, 4(1), Pp: 64-77

[11] V. Murali Krishna,2016, Experimental investigation of heat transfer enhancement by using al2o3water nanofluid in a concentric tube heat exchanger, International Journal of Mechanical Engineering and Technology (IJMET) Volume 7, Issue 6, NovemberDecember 2016, Pp.449-458.

[12] Hiregoudar Yerrennagoudaru, Manjunatha.k, B.Vishnu Prasad , Sandeep .k ,S.Veeresh Kumar ,2016, Nano Fluids for Heat Exchanger International Journal of Engineering Science and Innovative Technology (IJESIT), Volume 5, Issue 4.Pp:82-89.

[13] Ebenezar Paul, S.Kalyan Yadav, Saravana Kumar,2014, Numerical simulation and enhancement of heat transfer using cuo/water nano-fluid and twisted tape with alternate axis, International Journal of Mechanical Engineering and Technology (IJMET), ISSN 0976 - 6340(Print), Volume 5, Issue 9, Pp. 323335 .

[14] R.Dharmalingam, K.K.Sivagnanaprabhu, J. Yogaraja, S. Gunasekaran, R. Mohan Experimental investigation of heat transfer characteristics of nanofluid using parallel flow, counter flow and shell and tube heat exchanger, Archive of mechanical engineering, VOL. LXII 2015. Pp: 509-522.

[15] Gamit Sandip D, Gopal kumar Deshmukh,2015, Numerical and experimental investigation of heat transfer in double pipe heat exchanger with inner and annular twisted tape, , International Journal of Engineering Research \& Science (IJOER), Vol-I, Issue5,Pp:9-12.

[16] V. Gnielinski, 1976, New equations for heat and mass transfer in turbulent pipe and channel flow, Int. Chem. Eng. 16 (1976) 359-368.

[17] Notter, R.H., Rouse, M.W., 1972, A solution to the Graetz problem - III, Fully developed region heat transfer rates, Chemical Engineering Science 27 pp 2073-2093.

[18] H. Blasius, Boundary layers in fluids with small friction, Z. Math. Phys. 56 (1908), Pp: 1-37.

[19] Petukhov B S (1970) Heat Transfer and Friction in Turbulent Pipe Flow with Variable Physical Properties, in J P Hartnett and T F Irvine, (eds), Advances in Heat Transfer, Academic Press, New York, pp. 504-564.

[20] www.Sigma-Aldrich.com

[21] J. C. Maxwell, A Treatise on Electricity and Magnetism, 2nd edn., Oxford University Press, Cambridge, UK (1904).

[22] A. Einstein, Investigation on Theory of Brownian Motion, first edn., Dover Publications, USA (1956)

[23] H. Usui, Y. Sano, K. Iwashita, A. Isozaki, 
International Journal of Applied Engineering Research ISSN 0973-4562 Volume 12, Number 18 (2017) pp. 7088-7095

(C) Research India Publications. https://dx.doi.org/10.37622/IJAER/12.18.2017.7088-7095

Enhancement of heat transfer by a combination of internally grooved rough tube and twisted tape, International Chemical Engineering 26 (1996) 97-104.

[24] S. Suresh, K.P. Venkitaraj, P. Selvakumar, Comparative study on thermal performance of helical screw tape inserts in laminar flow using $\mathrm{Al}_{2} \mathrm{O}_{3}$ /water and $\mathrm{CuO} /$ water nanofluids, Superlattices and Microstructures. 49 (2011) 608-622.

[25] S.M. Hashemi, M.A. Akhavan-Behabadi, An empirical study on heat transfer and pressure drop characteristics of $\mathrm{CuO}$-base oil nanofluid flow in a horizontal helically coiled tube under constant heat flux, International Communications in Heat Mass Transfer 39 (2012) 144151.

[26] K. Wongcharee, S. Eiamsa-ard, Heat transfer enhancement by using $\mathrm{CuO} /$ water nanofluid in corrugated tube equipped with twisted tape, International Communications in Heat and Mass Transfer. 39 (2012) 251-257.

[27] A.A. Abbasian Arani, J. Amani, Experimental study on the effect of $\mathrm{TiO}_{2}$-water nanofluid on heat transfer and pressure drop, Experimental Thermal and Fluid Science 42 (2012) 107. 